Bangladesh J. Bot. 44(1): 59-65, 2015 (March)

\title{
GENETIC DIVERSITY OF GUAR GENOTYPES (CYAMOPSIS TETRAGONOLOBA (L.) TAUB.) BASED ON AGRO-MORPHOLOGICAL TRAITS
}

\author{
A Manivannan ${ }^{1 *}$, CR Anandakumar $^{2}, \mathrm{R}_{\text {Ushakumari and GS Dahiya }}^{3}$ \\ Department of Plant Breeding \& Genetics, Agricultural College \& Research Institute, \\ Madurai, Tamil Nadu, India
}

Key words: Guar, Principal component analysis, Clustering, Diversity

\begin{abstract}
Twelve quantitative characters were taken under observation to estimate substantial variation and relationship among Guar (Cyamopsis tetragonoloba (L.)Taub.,Fam.: Fabaceae) genotypes and to identify the best performing lines suited to southern parts of India, where the potential of growing the guar crop throughout the year. Analysis of variation for such quantitative traits in diverse line showed considerable and dissimilar level of variability. The largest variation was found for days to maturity, plant height, pods per plant and cluster per plant. Single plant yield was significant positively correlated with primary branches per plant, secondary branch per plant, cluster per plant, pods per cluster, pods per plant, however pod length was significant but negatively correlated with single plant yield. Principal component analysis showed the amount of variation by principal components 1 to 5 viz., 38, 16.4, 12.5, 9.5 and 6.6\%, respectively. Clustering analysis based on various morphological traits assorted 42 guar genotypes into four main groups and six subclusters. Dendrogram based on hierarchal clustering grouped genotypes based on their morphological traits rather than geographic origin. Grouping of genotypes based on morphological traits is not always associated with their geographical origin. Out performed genotypes based higher yield potential, 100-seed weight, pods per plant and early maturity are identified for guar variety development and future breeding programme suited for South India.
\end{abstract}

\section{Introduction}

Guar (Cyamopsis tetragonoloba (L.) Taub., Fam.: Fabaceae) is commonly known as clusterbean. It is a completely self-fertile and highly self-pollinated plant with an upright habit and deep rooted system, belongs to the family of Leguminosae (Fabaceae), highly valued for its yield, greater nutritional importance and drought tolerance. Guar known for its endosperm bound polysaccharide gum known as galactomannan, which fetches huge value in shale energy production field (fracking in petroleum industries) and also in textile, paper, pharmaceutical, nutraceutical and cosmaceutical industries.

Guar especially for gum purpose mostly cultivated in northern India especially the states of Rajasthan, Haryana, Gujarat, Madhya Pradesh during kharif season only and to some extent at summer season. There is no crop establishment and flowering during winter season and cold periods since guar is photosensitive (quantitative short day plant). But, southern parts of India especially in the state of Tamil Nadu, there is congenial climatic condition prevails throughout the year, so it can be cultivated across the seasons in Tamil Nadu. In order to exploit the climatic pattern of Tamil Nadu, there was an attempt to evaluate the germplasm and characterize the potential line for further genotypic selection.

*Author for correspondence: <manivannan461@gmail.com>. ICAR Directorate of Maize Research, Indian Agricultural Research Institute, Pusa, New Delhi, India. ${ }^{2}$ Centre for Plant Breeding \& Genetics, Tamil Nadu Agricultural University, Coimbatore, Tamil Nadu, India. ${ }^{3}$ Department of Genetics and Plant Breeding, CCS Haryana Agricultural University, Hisar, India. 


\section{Materials and Methods}

Genetic evaluation of 42 guar accessions on the basis of agro-morphological traits was performed in specimen plots of Department of Plant Breeding and Genetics, Agriculture College and Research Institute, Madurai. Accessions were obtained from across the country which represents diverse eco-geographical zones of India. Experiment was conducted as per RBD with plot size of $3 \times 3 \mathrm{~m}^{2}$ during November, 2012. Three meter length row per entry with spacing of $45 \times 15 \mathrm{~cm}$ and all agronomical practices were followed. Harvesting was carried out when more than $75 \%$ plants pod in each accession turned brown in color.

Quantitative characters were taken into consideration for estimating substantial variation and relationship among guar genotypes. Twelve quantitative characters viz., plant height $(\mathrm{cm})$, primary branches per plant, secondary branches per plant, clusters per plant, pods per cluster, pod length $(\mathrm{cm})$, seeds per pod, pods per plant, 100-seed weight $(\mathrm{g})$, single plant yield $(\mathrm{g})$, days to 50 per cent flowering and days to maturity were considered for estimating genetic diversity. Mean values of accessions were computed for determining analysis of variance and correlation coefficients were estimated by using the formulae of Kwon and Torrie (1964). Principal component analysis (PCA) and cluster analysis were also performed to assess genetic diversity among guar accessions.

\section{Results and Discussion}

Twelve quantitative traits were observed for all 42 guar accessions and observations were recorded for further analysis. Analysis of variation depicted considerable level of variability among different accessions for most of the traits. Basic descriptive statistics for 12 characters was presented in Table 1.

The largest variation was found for days to maturity, plant height, pods per plant and cluster per plant, these results were in agreement with findings of Sultan et al. (2012). Comparatively, low variation was noticed for seeds per pod, 100 -seed weight, secondary branches per plant, pod length, pods per cluster and days to 50 per cent flowering, these results were in agreement with the findings of Morris (2010), Sultan et al. (2012) and Gopalakrishnan et al. (2011). Observed variability found among guar accessions can be probably attributed to the genetic differences and the environment, in which these accessions were grown.

Correlation coefficient for different quantitative characters was presented in Table 2. Single plant yield was positively correlated with primary branches per plant, secondary branch per plant, cluster per plant, pods per cluster, pods per plant, these results were in agreement with the findings of Rai et al. (2012) and Sultan et al. (2012). The character 100-seed weight was negatively correlated with pods per plant, pods per cluster and primary branch per plant, while it showed positive correlation with pod length and seeds per pod. The character pods per cluster was negative correlation with pod length, seed per pod and 100-seed weight, while it showed positive correlation with pods per plant and single plant yield, these results were in agreement with the findings of Morris (2010).

PCA showed the amount of variation by principal components (PCs) 1 to 5 viz. 38, 16.4, 12.5, 9.5 and $6.6 \%$, respectively. The first PC was correlated with pods per plant, branches per plant, cluster per plant and single plant yield (Table 3). The second PC was associated with 100-seed weight, pod length, cluster per pod and seed per pod. The third PC was correlated with plant height, seed per pod and single plant yield. The fourth PC was correlated with days to maturity and days to 50 per cent flowering. The fifth PC was correlated with days to 50 per cent flowering. Hierarchical cluster analysis based on quantitative traits divided guar genotypes into four main groups and six sub-clusters (Fig. 1, Table 4). Maximum number of genotypes was in group II and 


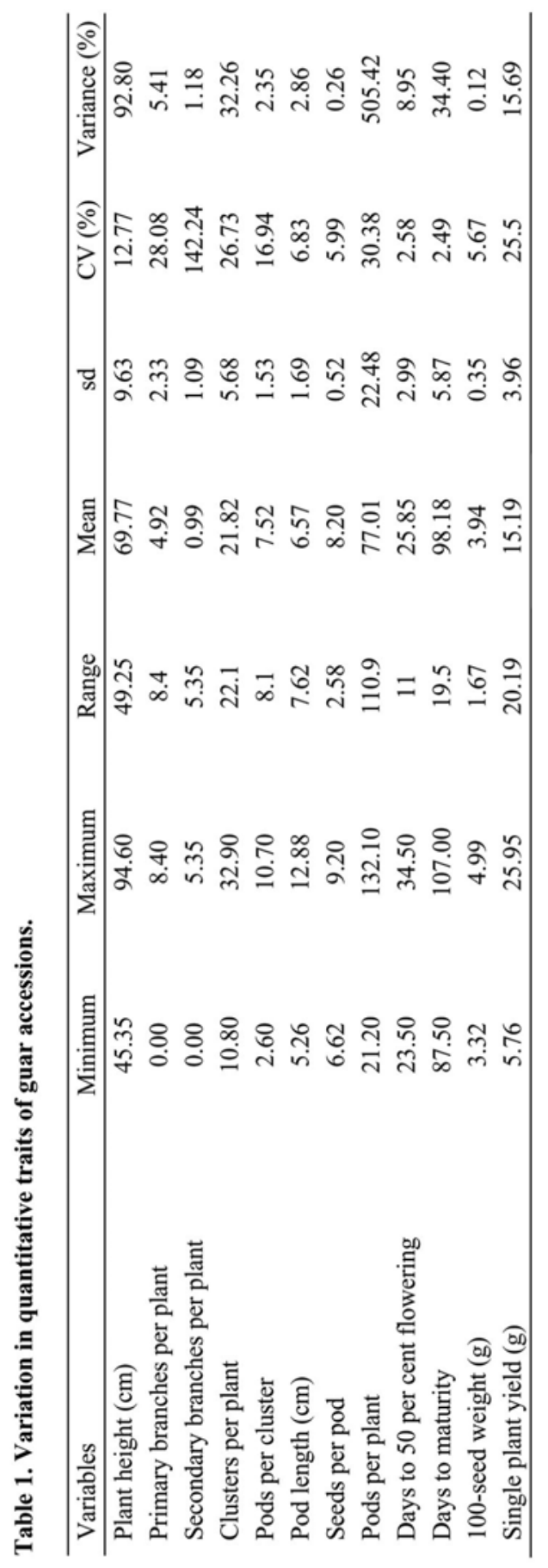




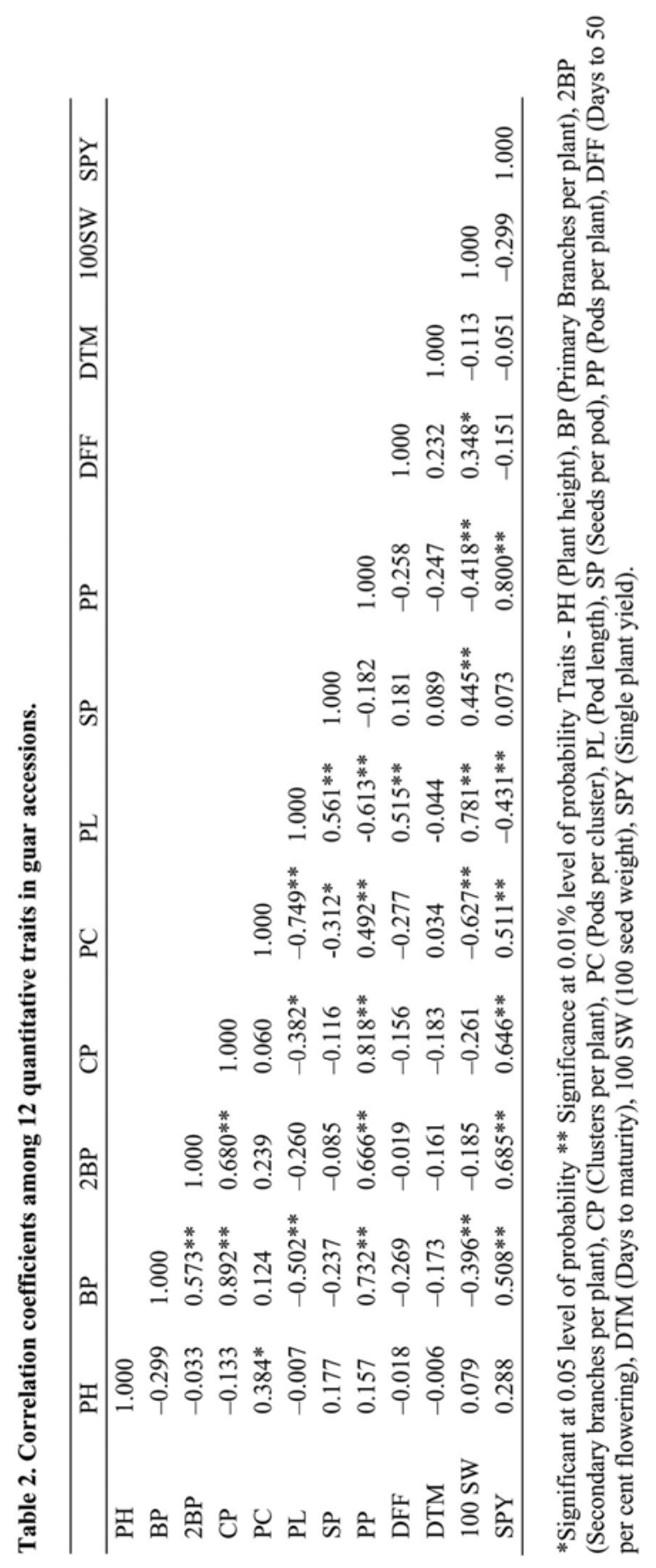


III (14 accessions each), followed by groups I and IV (4 accessions each). Groups II and III exhibited two sub-clusters each. Accessions of group I were characterized as higher 100 seed weight, pod length and seed per pod, lower in single plant yield, pods per plant, shorter in height and late in flowering (Table 5). In, sub-cluster 1 of group II accessions exhibited characteristics of late maturity, low single plant yield and 100-seed weight and short in height. However, higher in pods per cluster, taller in height, medium in single plant yield, higher 100-seed weight characteristics were showed by sub cluster 2 of group II. Early in maturity and flowering, higher pods per plant and medium in single plant yield were observed in sub cluster 1 of group III, however, sub-cluster 2 exhibited higher single plant yield and 100 seed weight, very late in maturity. Among four groups, group IV distinctly exhibited higher single plant yield, 100-seed weight, pods per plant and clusters per plant, highly branched and tall in height.

Table 3. Eigen vectors, principal components for quantitative traits in guar accessions.

\begin{tabular}{lccccc}
\hline Traits & \multicolumn{5}{c}{ Principal components (PCs) } \\
& 1 & 2 & 3 & 4 & 5 \\
\hline Plant height (cm) & 0.029 & -0.192 & 0.845 & -0.260 & -0.092 \\
Primary branches per plant & 0.796 & 0.336 & -0.333 & 0.150 & -0.112 \\
Secondary branches per plant & 0.688 & 0.462 & 0.123 & 0.107 & 0.198 \\
Clusters per plant & 0.786 & 0.501 & -0.116 & 0.168 & -0.127 \\
Pods per cluster & 0.607 & -0.581 & 0.380 & -0.108 & 0.204 \\
Pod length (cm) & -0.795 & 0.540 & 0.115 & -0.038 & 0.033 \\
Seeds per pod & -0.369 & 0.465 & 0.488 & 0.019 & -0.096 \\
Pods per plant & 0.912 & 0.187 & 0.182 & 0.019 & -0.150 \\
Days to 50 per cent flowering & -0.415 & 0.307 & 0.200 & 0.505 & 0.331 \\
Days to maturity & -0.179 & -0.310 & 0.154 & 0.739 & 0.277 \\
100-Seed weight (g) & -0.646 & 0.547 & 0.173 & -0.129 & -0.143 \\
Single plant yield (g) & 0.769 & 0.223 & 0.483 & 0.092 & 0.015 \\
\hline
\end{tabular}

Table 4. Mean of quantitative traits of guar accessions.

\begin{tabular}{lcccc}
\hline Traits & Group I & Group II & Group III & Group IV \\
\hline Plant height $(\mathrm{cm})$ & 64.18 & 82.30 & 69.01 & 73.50 \\
Primary branches per plant & 1.15 & 1.88 & 6.30 & 7.56 \\
Secondary branches per plant & 0.00 & 0.17 & 1.44 & 2.49 \\
Clusters per plant & 14.32 & 13.88 & 25.04 & 30.74 \\
Pods per cluster & 4.20 & 8.71 & 7.73 & 7.84 \\
Pod length (cm) & 11.02 & 6.53 & 6.02 & 6.25 \\
Seeds per Pod & 8.87 & 8.22 & 8.11 & 8.51 \\
Pods per plant & 34.12 & 63.31 & 86.81 & 121.48 \\
Days to 50 per cent flowering & 30.62 & 25.42 & 24.53 & 27.50 \\
Days to maturity & 98.50 & 99.59 & 95.10 & 95.00 \\
100-seed weight $(\mathrm{g})$ & 4.78 & 3.99 & 3.89 & 3.93 \\
Single plant yield $(\mathrm{g})$ & 9.27 & 14.14 & 16.55 & 21.31 \\
\hline
\end{tabular}

Cluster analysis using Ward's method of minimum variance showed distinct pattern of group formation. Cluster I possessed the accessions of vegetable purpose and all other clusters possessed the gum yield accessions. However, more accessions from different origins were clustered into same cluster. Grouping of accessions based on morphological, phenomical and reproductive characters is not always associated with their geographical origin. Present results were in accordance with the findings of Singh et al. (2005), Pervaiz et al. (2010), Pathak et al. (2010), Rai et al. (2012), Sultan et al. (2012), Girish et al. (2012) and Kumar et al. (2013). 
Table 5. Characteristics of guar accessions in sub-clusters.

\begin{tabular}{|c|c|c|c|c|}
\hline $\begin{array}{l}\text { Main } \\
\text { group }\end{array}$ & $\begin{array}{c}\text { Sub- } \\
\text { cluster }\end{array}$ & $\begin{array}{l}\text { No. of } \\
\text { lines }\end{array}$ & $\begin{array}{l}\% \text { of } \\
\text { lines }\end{array}$ & $\begin{array}{l}\text { Prominent } \\
\text { traits }\end{array}$ \\
\hline $\mathrm{I}$ & 1 & 4 & 9.52 & $\begin{array}{l}\text { Highest } 100 \text {-seed weight, highest pod length, highest seed per pod, } \\
\text { lowest single plant yield, lowest pods per plant, shorter in height, } \\
\text { late in flowering. }\end{array}$ \\
\hline \multirow[t]{2}{*}{ II } & 1 & 13 & 30.95 & Late maturity, low yield, lowest 100 -seed weight, short in height. \\
\hline & 2 & 4 & 9.52 & $\begin{array}{l}\text { highest pods per cluster, tallest in height, medium single plant yield, } \\
\text { high } 100 \text {-seed weight }\end{array}$ \\
\hline \multirow[t]{2}{*}{ III } & 1 & 6 & 14.28 & $\begin{array}{l}\text { Early in maturity, early in flowering, highest pods per plant, } \\
\text { medium in single plant yield, }\end{array}$ \\
\hline & 2 & 11 & 26.19 & $\begin{array}{l}\text { High single plant yield, high in } 100 \text {-seed weight, very late in } \\
\text { maturity }\end{array}$ \\
\hline IV & 1 & 4 & 9.52 & $\begin{array}{l}\text { Highest single plant yield, high in } 100 \text {-seed weight, highest number } \\
\text { of pods per plant, highest number of clusters per plant, Highly } \\
\text { branched type, tall in height }\end{array}$ \\
\hline
\end{tabular}

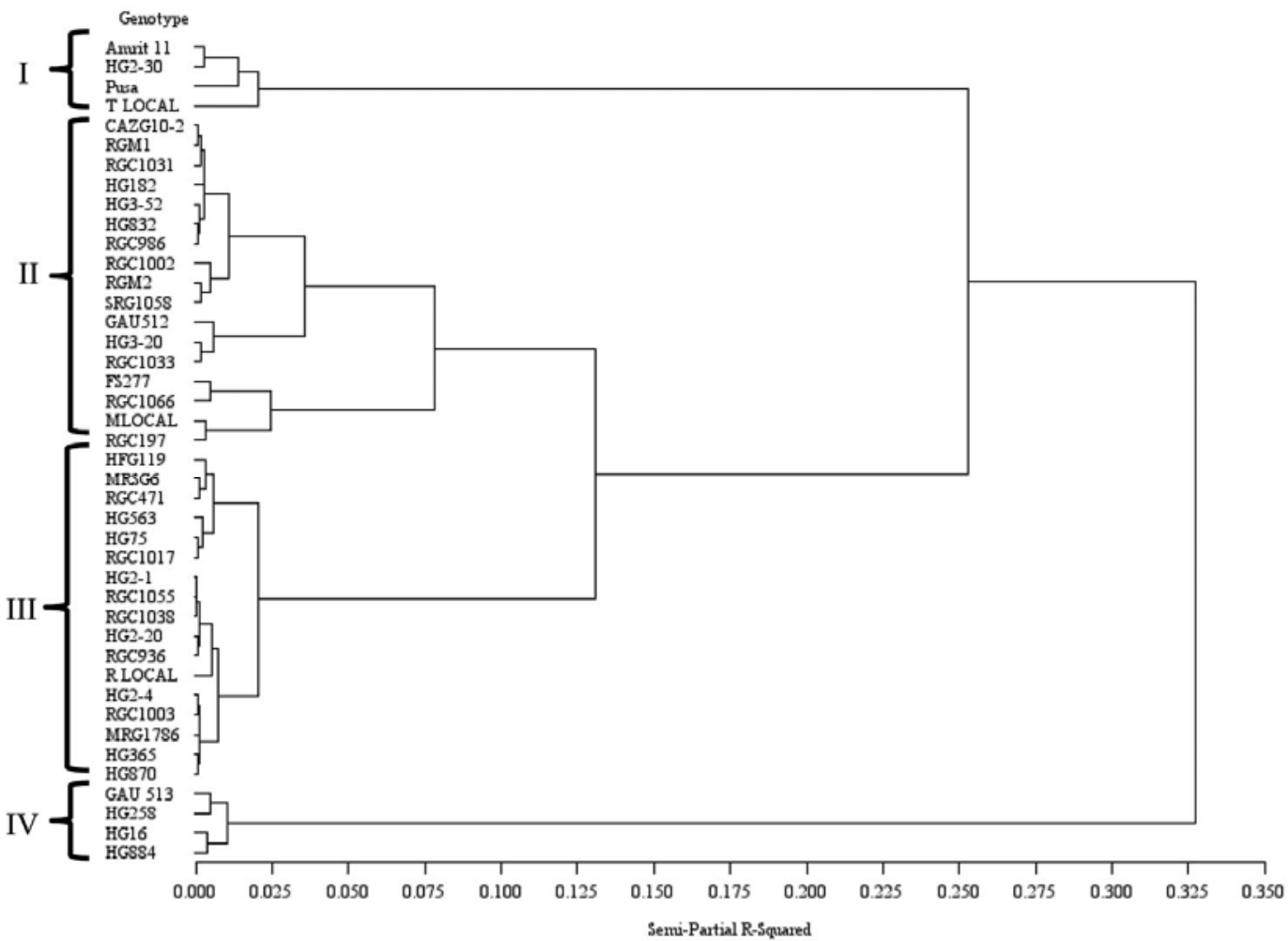

Fig. 1. Dendrogram based on cluster analysis for various agro-morphological traits of guar accessions. 
Table 6. Elite guar accessions identified on the basis of important agro-morphological traits.

\begin{tabular}{lll}
\hline Traits of interest & Range & Accessions identified \\
\hline Single plant yield $(\mathrm{g})$ & $\geq 17$ & GAU 513, HGS2-1, HGS2-20, HGS16, HGS2-4, HGS258, HGS75, \\
& & MRSG6, RGC1003, RGC1002 \\
100-seed weight $(\mathrm{g})$ & $\geq 3.9$ & $\begin{array}{l}\text { Amrit 11, CAZG10-2, FS277, HGS16, HGS182, HGS2-1, HGS2-20, } \\
\end{array}$ \\
& HVG2-30, HGS2-4, HGS884, M local, PNB, RGC1038, RGC1066, \\
& RGC197, T local \\
Pods per plant & $\geq 90$ & GAU 513, HGS16, HGS2-4, HGS258, HGS365, HGS75, HGS884, \\
& MRSG6, RGC1003, RGC1017, RGC471 \\
Days to maturity & $<90$ & GAU512, HFG119, HGS16, HG2-4, HGS3-52, HGS563, HGS75, \\
& HGS832, HGS884, MRSG6, PNB, CAZG10-2, RGC1003, RGC1017, \\
& RGC1066, RGC471, T local \\
\hline
\end{tabular}

Based on the results of present investigation, an extensive range of genetic diversity has been explored in guar accessions. Important agro-morphological traits like greater yield potential, seeds per pod, pods per plant and early maturity, etc., served as a criterion to select promising guar genotypes which will be suited to southern parts of India (Table 6). Cataloging and documenting the diversity of genotypes is essential for future guar breeding programme.

\section{References}

Girish MH, Gasti VD, Thammaiah N, Kerutagi MG, Mulge R, Shantappa T and Mastiholi AB 2012. Genetic divergence studies in cluster bean genotypes (Cyamopsis tetragonoloba (L.) Taub.). Karnataka J. Agric. Sci. 25: 245-247.

Gopalakrishnan S, Dwivedi NK and Singh JP 2011. Primitive weedy forms of guar, adak guar: possible missing link in the domestication of guar Cyamopsis tetragonoloba(L.). Genet. Resour. Crop Evol. 58: 961-96.

Kumar S, Joshi UN, Singh V, Singh JV and Saini ML 2013. Characterization of released and elite genotypes of guar (Cyamopsis tetragonoloba (L.) Taub.) from India proves unrelated to geographical origin. Genet. Resour. Crop Evol.DOI 10.1007/s10722-013-9970-7

Kwon SH and Torrie JH 1964. Heritability and interrelationship of traits of soybean populations. Crop Sci. 4: 196-198.

Morris JB 2010. Morphological and reproductive characterization of guar (Cyamopsis tetragonoloba) genetic resources regenerated in Georgia, USA. Genet. Resour. Crop. Evol .57: 985-993.

Pathak R, Singh SK, Singh M and Henry A 2010.Molecular assessment of genetic diversity in cluster bean (Cyamopsis tetragonoloba) genotypes. J. Genet. 89: 243-246.

Pervaiz ZH, Rabbani MA, Khaliq I, Pearce SR and Malik SA 2010. Genetic diversity associated with agronomic traits using microsatellite markers in Pakistani rice landraces. Elect. J. Biotech.13: 1-12.

Rai PS, Dharmatti PR, Shashidhar TR, Patil RV and Patil PR 2012. Genetic variability studies in clusterbean (Cyamopsis tetragonoloba (L.) Taub). Karnataka J. Agric. Sci. 25: 108-111.

Singh RV, Chaudhary SPS, Singh J and Singh NP 2005. Genetic divergence in cluster bean (Cyamopsis tetragonoloba L.). Arid Legumes for Sustainable Agriculture and Trade 1: 102-105.

Sultan M, Yousaf MN, Rabbani MA, Shinwari ZK and Masood MS 2012. Phenotypic divergence in guar (Cyamopsis tetragonoloba L.) landrace genotypes of Pakistan. Pak. J. Bot. 44: 203-210. 